\title{
O ENSAIO COMO FORMA EM WALTER BENJAMIN: CONTRIBUIÇÕES DO GÊNERO ENSAÍSTICO PARA A EDUCAÇÃO
}

Maria Cecília Paladini Piazza

\begin{abstract}
RESUMO
Este artigo tem por intenção investigar o ensaio como forma em Walter Benjamin e tentar compreender as contribuições do legado de Benjamin à educação por meio da leitura de seus ensaios. Além disso, busca mostrar de que maneira a escrita ensaística do autor responde às temáticas sobre experiência, narratividade, progresso e história. Para tanto, num primeiro momento, será realizado um rápido percurso pela história de Benjamin. Por conseguinte, discutir-se-á as reflexões de Theodor Adorno em seu texto "O ensaio como forma". Num segundo momento este estudo apresenta o conceito de experiência e narratividade na obra do autor e sua relação com a tradição e a educação. Num terceiro momento, procura-se discutir as noções de progresso e história. Por último, este artigo tenta aproximar o conceito benjaminiano de ensaio e o processo educativo.
\end{abstract}

Palavras-chave: Educação. Ensaio. Experiência. História. Progresso.

\section{EI ENSAYO COMO FORMA EN WALTER BENJAMIN: CONTRIBUICIONES DEL GÉNERO ENSAYSTICO PARA EDUCACIÓN}

\section{RESUMEN}

Este artículo tiene por intención investigar el ensayo como forma en Walter Benjamin y comprender las contribuciones del legado de Benjamin a la educación por medio de la lectura de sus ensayos. Además, el trabajo busca mostrar de que manera la escrita ensayística del autor responde a las temáticas sobre experiencia, narratividad, progreso, historia y modernidad. Para tanto, en un primer momento, será realizado un rápido recorrido por la historia de Benjamin. Por consiguiente irá discutir las reflexiones de Theodor Adorno en su texto "El ensayo como forma". En un segundo momento este estudio presenta el concepto de experiencia $y$ narratividad en la obra do autor y su relación con la tradición y la educación. En un tercero momento, se busca discutir las nociones de progreso e historia. Por último, esta pesquisa intenta aproximar el concepto benjaminiano de ensayo y el proceso educativo.

Palabras-Ilave: Educación. Ensayo. Experiencia. Progreso. Historia.

Mestre em Educação pela Universidade do Extremo Sul Catarinense. Graduada em Letras-Português e Espanhol pela Universidade do Extremo Sul Catarinense. Especialização em Língua e Literatura com ênfase nos gêneros discursivos pela Universidade do Extremo Sul Catarinense. Atualmente está cursando disciplina de doutorado em Educação pela Universidade Federal de Santa Catarina. Brasileira, residente em Santa Catarina. E:mail: cissapiazza@yahoo.com.br. 
Este artigo é resultado de uma dissertação de mestrado que consiste em investigar o ensaio como forma em Walter Benjamin e compreender as contribuições do legado de Benjamin à educação por meio da leitura de seus ensaios. Além disso, este trabalho busca mostrar de que maneira a escrita ensaística do autor responde às temáticas sobre experiência, narratividade, progresso e história. Dessa maneira, serão analisados alguns textos de Benjamin a fim de perceber o lugar do ensaio no contexto da educação. De resto, busca-se também investigar como se dá a relação entre educação, experiência e narratividade a partir das teorias do autor.

Talvez fosse necessário, antes de qualquer coisa, esclarecer que a investigação do ensaio como forma em Benjamin busca relacioná-lo com a educação não numa perspectiva metodológica, instrumental e doutrinária, mas no aspecto associado ao estilo de sua linguagem que possibilita a abertura de expor o pensamento, pois não pretende oferecer conteúdos acabados. Nesse sentido, para subsidiar esse raciocínio, será analisado no decorrer deste artigo as reflexões de Adorno em seu texto "O ensaio como forma", que se encontra na coletânea intitulada Notas de literatura. Em seu texto, Adorno destaca o caráter conceitual do ensaio e suas singularidades, apontando que tal gênero textual não se prende a um método pré-estabelecido. Nessa perspectiva, o questionamento que norteará este trabalho é: de que maneira o ensaio como forma benjaminiano pode contribuir para refletir sobre o processo educativo?

Destaca-se que este estudo se caracteriza por ser uma pesquisa bibliográfica desenvolvida com base em material já elaborado, constituído principalmente de livros e ensaios de Benjamin, assim como de seus principais leitores. Salienta-se também que as reflexões benjaminianas abrangem diferentes temas escritos de maneira ensaística, dialogando com diversas áreas do conhecimento e quase sempre prevalecendo a assistematicidade e extrema liberdade que o gênero oferece. Além disso, conforme defende Adorno no célebre "O ensaio como forma", este gênero possibilita abordar diferentes assuntos sem a obrigação de se prender a nenhum deles, pois o ensaio permite experimentar os objetos sem a pretensão de nos dar a palavra ou o conceito final sobre determinado assunto. Adorno também

Mestre em Educação pela Universidade do Extremo Sul Catarinense. Graduada em Letras-Português e Espanhol pela Universidade do Extremo Sul Catarinense. Especialização em Língua e Literatura com ênfase nos gêneros discursivos pela Universidade do Extremo Sul Catarinense. Atualmente está cursando disciplina de doutorado em Educação pela Universidade Federal de Santa Catarina. Brasileira, residente em Santa Catarina. E:mail: cissapiazza@yahoo.com.br. 
defende o ensaio, até então considerado menor na Alemanha, e aponta que a qualidade principal do gênero em questão diz respeito à liberdade que a escritura assume. Ainda segundo Adorno, Walter Benjamin seria o "mestre insuperável" (2003: 29) do ensaio, pela profundidade e capacidade artística de seus escritos.

Crítico do romance alemão, leitor dos escritores como Proust e Baudelaire, Benjamin radicaliza a forma de ver o mundo e de maneira pouco ortodoxa analisa fenômenos históricos, processos sociais e lutas políticas, valendo-se de elementos tirados do romantismo alemão, da teologia judaica cristã e do materialismo histórico. Para Löwy (2010), Benjamin elabora um pensamento único que permite uma espécie de integração entre o messianismo, o romantismo e o materialismo. Além disso, o ensaísta alemão de origem judaica ${ }^{1}$ é historiador e discute a questão da modernidade e da urbanidade na Europa do século XIX. Por isso, de acordo com Jeanne Marie Gagnebin (1999), não se deve sustentar interpretações apressadas e globalizantes em relação aos ensaios do autor.

Em relação à biografia de Benjamin, ${ }^{2}$ é imperativo contextualizar que o autor é fruto do seu tempo histórico e sendo assim vivenciou os efeitos das contradições que uma época histórica produz em um indivíduo, pois o filósofo esteve no centro de alguns dos maiores e mais dramáticos acontecimentos da Europa, como a Segunda Guerra Mundial.

Sendo assim, a fim de analisar o ensaio como forma em Benjamin, partiremos, num primeiro momento, para a investigação do conceito de experiência e narratividade na obra do autor e sua relação com a tradição e a educação. Para esta análise, textos de Benjamin como "Experiência e pobreza" (1933), "O Narrador" (1936) e "Alguns temas em Baudelaire" (1939) serão explorados a fim de compreendermos a perda da experiência tal como formulada pelo autor. Conforme Jeanne Marie Gagnebin explica, a crítica de Benjamin, nestes ensaios, é a de que as relações sociais têm sido esvaziadas e a humanidade perdeu a capacidade de

1 É importante esclarecer que o pensamento benjaminiano se conduz nos valores teológicos judaicos que, por sua vez, referem-se a uma teologia que não permite nomear ou fazer imagens de Deus, ou seja, Deus é um ser superior que está acima de qualquer compreensão humana.

2 O contexto que Benjamin, cronologicamente, vivencia e no qual está inserido é entre as duas guerras mundiais. Isso permite que se faça uma inferência sobre a razão de o filósofo enxergar a história sob um ponto de vista tão dramático e trágico.

Mestre em Educação pela Universidade do Extremo Sul Catarinense. Graduada em Letras-Português e Espanhol pela Universidade do Extremo Sul Catarinense. Especialização em Língua e Literatura com ênfase nos gêneros discursivos pela Universidade do Extremo Sul Catarinense. Atualmente está cursando disciplina de doutorado em Educação pela Universidade Federal de Santa Catarina. Brasileira, residente em Santa Catarina. E:mail: cissapiazza@yahoo.com.br. 
trocar experiências, ou seja, o homem está mais pobre de "experiências comunicáveis" (BENJAMIN, 1986: 115). No campo da educação, essas temáticas serão discutidas a fim de percebermos qual a relação existente entre educação, experiência e narratividade em Benjamin. Por fim, mostrar a aproximação que há entre essas temáticas e o processo educativo.

Num segundo momento discutem-se as noções de progresso e história, considerados evidentemente sob o ponto de vista benjaminiano, abordando a preocupação do autor em relação à herança que a concepção linear de história deixa para o mundo. De acordo com Löwy (2010), Benjamin quer romper com a linearidade a fim de mostrar uma outra dimensão da história e do tempo, sendo que há múltiplas histórias simultâneas e não uma lógica da história que é posta de maneira superior. Para Benjamin, o processo de releitura do passado deve ser contínuo, pois nenhuma releitura é definitiva, trata-se de um olhar voltado para o passado, mas não tal como foi contado, e sim para aquilo que não foi dito acerca dele. O resultado, é claro, seria uma nova leitura do tempo presente.

Para esta análise será discutido o texto "Sobre o conceito da história", que, segundo Löwy, é um dos textos filosóficos e políticos mais importantes dos século $X X$. Além disso, também discute-se o texto "A vida dos estudantes", no qual o filósofo pontua a força do sistema financeiro sobre a educação e a produção intelectual, argumentando que a consequência da noção de "utilidade" é a carência de conhecimento crítico e autêntico, pois, na universidade, o indivíduo que poderia dedicar-se a uma ciência empenhada no rigor intelectual acaba por deixar esvaecer sua identidade e se entrega à ilusão do progresso capitalista.

O terceiro momento deste artigo tenta mostrar a aproximação que há entre o ensaio e o processo educativo, assinalando quais as contribuições da escrita ensaística benjaminiana para a educação. Além disso, em vista do que foi dito anteriormente o texto mostra de que maneira a escrita de Benjamin responde às temáticas de experiência, narratividade, história e progresso a partir de uma estratégia textual particular.

Dessa forma, formulamos questões pertinentes ao presente estudo que são as seguintes: de que modo o ensaio como forma contribui para o processo educativo

Mestre em Educação pela Universidade do Extremo Sul Catarinense. Graduada em Letras-Português e Espanhol pela Universidade do Extremo Sul Catarinense. Especialização em Língua e Literatura com ênfase nos gêneros discursivos pela Universidade do Extremo Sul Catarinense. Atualmente está cursando disciplina de doutorado em Educação pela Universidade Federal de Santa Catarina. Brasileira, residente em Santa Catarina. E:mail: cissapiazza@yahoo.com.br. 
a partir de uma leitura benjaminiana? Como é possível perceber a relação existente entre educação, experiência e narratividade em Benjamin? Como se pode perceber, no ensaio como forma em Walter Benjamin, a resistência à noção de história linear e progresso? De que maneira o ensaio como forma em tal autor responde às temáticas de experiência, narratividade, história e progresso?

Pensar no legado do ensaio como forma em Benjamin pressupõe a possibilidade de entendê-lo como uma constante experiência sobre o conhecimento, ou seja, o fato de esse filósofo pretender experimentar e ensaiar nos faz refletir sobre o quanto esta educação direcionada para prática profissional institucionaliza isola o saber. O ensaio benjaminiano permite refletir e repensar sobre as concepções racionalistas da educação, que afastam cada vez mais o sujeito do coletivo, da vida humana, dos laços com as tradições e gerações, pois o ritmo acelerado e pautado no progresso não permite que consigamos nos orientar para construir críticas sociais mais relevantes e embasadas no bem comum. $O$ ensaio como forma demonstra que a formação deve também ter esse caráter mais aberto que possibilita criar e recriar questões referentes ao processo educativo. Importante enfatizar que Benjamin não traz uma proposta educacional, na verdade acredito que ele seja contra a ideia de qualquer plano tanto para o campo da educação quanto para outro setor.

\title{
O CONCEITO DE EXPERIÊNCIA E NARRATIVIDADE EM WALTER BENJAMIN
}

\begin{abstract}
O que foi feito de tudo isso? Quem ainda encontra pessoas que saibam contar histórias como elas devem ser contadas? Que moribundos dizem hoje palavras tão duráveis que possam ser transmitidas como um anel, de geração em geração? Quem é ajudado, hoje, por um provérbio oportuno? Quem tentará, sequer, lidar com a juventude invocando sua experiência? (BENJAMIN, 1986: 114).
\end{abstract}

Para o pensador alemão, a "cotação de experiência baixou", e numa visão reveladora traz sua sentença: "Uma miséria totalmente nova se abateu sobre o homem com este desenvolvimento monstruoso da técnica" (1986: 195). Para o filósofo, as experiências que eram antes comunicadas entre as gerações e

Mestre em Educação pela Universidade do Extremo Sul Catarinense. Graduada em Letras-Português e Espanhol pela Universidade do Extremo Sul Catarinense. Especialização em Língua e Literatura com ênfase nos gêneros discursivos pela Universidade do Extremo Sul Catarinense. Atualmente está cursando disciplina de doutorado em Educação pela Universidade Federal de Santa Catarina. Brasileira, residente em Santa Catarina. E:mail: cissapiazza@yahoo.com.br. 
transmitidas num ritmo lento, pautado na tradição comunicativa, entraram em decadência; a rigor, esse empobrecimento está relacionado à incapacidade de narrar (contar histórias). Evidencia-se a postura de Benjamin nesta passagem de "Experiência e pobreza”, um ensaio breve que trata de questões historiográficas relativas à memória após a Segunda Guerra Mundial:

\begin{abstract}
Sabia-se exatamente o significado da experiência: ela sempre fora comunicada aos jovens. De forma concisa, com a autoridade da velhice, em provérbios; de forma prolixa, com a sua loquacidade, em histórias; muitas vezes como narrativas de países longínquos, diante da lareira, contadas a pais e netos. Que foi feito de tudo isso? Quem encontra ainda pessoas que saibam contar histórias como elas devem ser contadas? (1986: 195).
\end{abstract}

Dessa forma, em seu ensaio "Experiência e pobreza" (1933), Benjamin discorre que a retração da transmissão de experiências foi fomentada pela dissolução do modelo familiar patriarcal e pelo trauma europeu devido à Primeira Guerra Mundial. Por isso, as experiências das antigas gerações, que eram passadas aos mais jovens através das parábolas, fábulas, histórias, provérbios e baseadas na construção da tradição e da memória, encontram-se em declínio acentuado. Benjamin exemplifica o sentido da tradição e da memória como princípio e transmissão do saber, relatando, no início do texto "Experiência e pobreza", uma fábula sobre um tesouro enterrado na vinha. Em poucas palavras, a fábula expressa um legado que não depende do tempo, pois é capaz de ser transmitido de geração em geração e de servir também como conselho. Assim ele narra:

\begin{abstract}
Em nossos livros de leitura havia a parábola de um velho que no momento da morte revela a seus filhos a existência de um tesouro enterrado em seus vinhedos. Os filhos cavam, mas não descobrem qualquer vestígio do tesouro. Com a chegada do outono, as vinhas produzem mais que qualquer outra na região. Só então compreenderam que o pai Ihes havia transmitido uma certa experiência: a felicidade não está no ouro, mas no trabalho (BENJAMIN, 1986: 114).
\end{abstract}

Infere-se, por meio da parábola, que, segundo Benjamin (1986: 105), a experiência é a "matéria da tradição, tanto na vida privada quando na coletiva". Ela é um tipo de saber que se mantém num espaço e tempo para além do racional, ou seja, não está condicionada pelo tempo, e por isso sustenta o fazer e o saber de

Mestre em Educação pela Universidade do Extremo Sul Catarinense. Graduada em Letras-Português e Espanhol pela Universidade do Extremo Sul Catarinense. Especialização em Língua e Literatura com ênfase nos gêneros discursivos pela Universidade do Extremo Sul Catarinense. Atualmente está cursando disciplina de doutorado em Educação pela Universidade Federal de Santa Catarina. Brasileira, residente em Santa Catarina. E:mail: cissapiazza@yahoo.com.br. 
uma coletividade/comunidade. Da mesma forma, a questão da tradição, demonstrada nesta parábola, contextualiza as ações e mostra de que maneira as pessoas se relacionam umas com as outras.

Além disso, naquela época, Benjamin já percebia que o crescimento das massas e a maneira como o homem moderno se movimentava impossibilitava a invocação do saber da tradição, restando-lhe apenas silenciar diante da realidade. Dito isso em relação à perda da experiência, Benjamin problematiza: "A quem ajuda, hoje em dia, um provérbio? Quem sequer tentará lidar com a juventude invocando sua experiência?" (1986: 195).

Benjamin indica, com efeito, que a sociedade moderna inviabiliza qualquer chance e intenção de estabelecer um trabalho coletivo que vislumbre uma postura e atitude em prol da transformação da realidade social, pois troca os princípios sociais do modo de vida comunitário de antigamente pelo individualismo e interesse próprios. E, consequentemente, faz gerar uma nova forma de miséria. O homem moderno, criticado por Benjamin, é aquele que não realiza a experiência (Erfahrung), já que concentra seus momentos apenas na superficialidade do consumismo, das sensações de uma racionalidade calculista que dificulta qualquer tipo de reflexão.

No ensaio "O Narrador: considerações sobre a obra de Nikolai Leskov" (1936), Benjamin analisa a obra de Leskov, que simboliza algo que está desaparecendo: o contador de histórias. Assim como no ensaio "Experiência e pobreza", citado acima, o autor ainda prova estar impactado com a evolução técnica da sociedade moderna. Entretanto, o filósofo agora aborda o problema da experiência numa outra perspectiva, ou seja, Benjamin discute não apenas a relação dos efeitos da técnica na subjetividade das vanguardas artísticas mencionadas no texto "Experiência e pobreza", mas também discorre sobre o homem que transmitia a experiência: o contador de histórias. Nas palavras de Benjamin,

Contar histórias sempre foi a arte de contá-las de novo, e ela se perde quando as histórias não são mais conservadas, ela se perde porque ninguém mais fia ou tece enquanto ouve a história. Quanto mais o ouvinte se esquece de si mesmo, mais profundamente se grava nele o que é ouvido (1986, p. 204-205).

Mestre em Educação pela Universidade do Extremo Sul Catarinense. Graduada em Letras-Português e Espanhol pela Universidade do Extremo Sul Catarinense. Especialização em Língua e Literatura com ênfase nos gêneros discursivos pela Universidade do Extremo Sul Catarinense. Atualmente está cursando disciplina de doutorado em Educação pela Universidade Federal de Santa Catarina. Brasileira, residente em Santa Catarina. E:mail: cissapiazza@yahoo.com.br. 
No ensaio "Sobre alguns temas em Baudelaire", Benjamin (1939) recorre ao poeta e desenvolve, de maneira mais clara e a partir da análise de seus poemas líricos, as noções de "experiência plena" (Erfahrung) e "experiência de choque" (Chockerlebnis) ou "vivência" (Erlebnis). Assim, a poesia de Baudelaire se torna, para Benjamin, um território capaz de desvendar os pormenores da escrita poética e, dessa forma, de responder à seguinte pergunta: "de que modo a poesia lírica poderia estar fundamentada em uma experiência para qual o choque se tornou a norma?" (BENJAMIN, 1989: 110).

Nesse sentido, Benjamin desvela, na lírica de Baudelaire, problemas e conceitos que estão relacionados à experiência. Assim, Gagnebin (1999) diferencia duas palavras essenciais em Benjamin: Erfahrung e Erlebnis. A primeira representa a experiência que está vinculada a uma temporalidade compartilhada com diversas gerações. Conforme Gagnebin explica, a experiência resulta de:

\begin{abstract}
Uma tradição compartilhada e retomada na continuidade de uma palavra transmitida de pai para filho: continuidade e temporalidade das sociedades "artesanais" diz Benjamin em "O Narrador," em oposição ao tempo deslocado e entrecortado do trabalho no capitalismo moderno (GAGNEBIN, 1999: 65-66).
\end{abstract}

Como observa Gagnebin, para Benjamin a Erfahrung é a sabedoria que se constitui historicamente e é difundida pela tradição, ou seja, a referência de Benjamin à verdadeira experiência agrega-se a um julgamento de valor moral e histórico e refere-se a algo que se dá na coletividade.

Por outro lado, o termo Erlebnis significa vivência, ou seja, a experiência do choque que seria um tempo fadado à repetição, ao eterno retorno do mesmo, caracterizado como um exemplo de experiência inferior e improdutivo no âmbito da ação humana. Para Benjamin, nenhuma significação pode ser atribuída a uma vivência, pois ela conclui sua ação no mesmo momento de seu próprio aparecimento.

Sendo assim, infere-se que tanto Benjamin quanto Baudelaire se indignam em torno da maneira com que o mundo se conduz e querem que o poeta moderno, antigo "bebedor de quintessências" (BAUDELAIRE, 2006: 189), se revolte com a

Mestre em Educação pela Universidade do Extremo Sul Catarinense. Graduada em Letras-Português e Espanhol pela Universidade do Extremo Sul Catarinense. Especialização em Língua e Literatura com ênfase nos gêneros discursivos pela Universidade do Extremo Sul Catarinense. Atualmente está cursando disciplina de doutorado em Educação pela Universidade Federal de Santa Catarina. Brasileira, residente em Santa Catarina. E:mail: cissapiazza@yahoo.com.br. 
falta de sentido que há no fetichismo pela mercadoria e no desenvolvimento tecnológico.

No campo da educação, os temas discutidos acima ajudam a compreender a necessidade de, primeiramente, distinguir e entender a noção de experiência plena e vivência, como foi explicado anteriormente. A primeira consiste em uma ação refletida, rememorada, compartilhada, perdurando e mantendo-se com a característica de ser atemporal, pois nela há a socialização e a transmissão de um tipo de experiência verdadeira. Já a segunda é uma ação que se dissipa no instante de sua realização; trata-se de um tipo inferior de experiência, pois é improdutiva no campo da ação humana.

É nesse sentido que essas reflexões evidenciam a necessidade de diferenciálas. Apesar de que, para Benjamin, não é possível, no mundo moderno, transformar as vivências em experiências no sentido compreendido pelo filósofo, ao menos devemos estar conscientes e ter discernimento de que as vivências são menos efetivas para uma educação voltada para a tradição e para o coletivo.

\section{HISTÓRIA E PROGRESSO EM WALTER BENJAMIN}

\footnotetext{
O conceito de progresso deve ser fundamentado na ideia de catástrofe. Que "as coisas continuem assim", eis a catástrofe (BENJAMIN, 1986: 515).
}

No segundo momento deste artigo discute-se a concepção de história e progresso elaborada por Walter Benjamin por meio de dois de seus escritos sobre tal temática, a saber: "As teses sobre o conceito de história" (1940) e "A vida dos estudantes" (1915). Nesses dois textos, Benjamin se ocupa em discutir sobre o caráter destrutivo da marcha temporal do progresso e da história, apontando a importância de romper com a história linear e deter o rumo da história, pois ela não acontece como se fosse uma linha reta.

Além do mais, novamente ele discute a experiência da vida moderna como afastada e separada da tradição. Dessa maneira, preservar e retomar a tradição é fundamental para lutar contra o conceito da história progressista e reconsiderar a história sob outras perspectivas; e, acima de tudo, perceber o quanto é enganosa e

Mestre em Educação pela Universidade do Extremo Sul Catarinense. Graduada em Letras-Português e Espanhol pela Universidade do Extremo Sul Catarinense. Especialização em Língua e Literatura com ênfase nos gêneros discursivos pela Universidade do Extremo Sul Catarinense. Atualmente está cursando disciplina de doutorado em Educação pela Universidade Federal de Santa Catarina. Brasileira, residente em Santa Catarina. E:mail: cissapiazza@yahoo.com.br. 
ilusória a ideia da continuidade da história. Para Benjamin, o importante não é a sucessão de fatos históricos, a partir de uma dimensão quantitativa e acumulativa, mas sim a compreensão do seu caráter descontínuo e a necessidade de que esteja aberta de todos os lados.

No curto e notável documento "A vida dos estudantes" (1914-1915), Benjamin revela que as condições do processo de modernização da sociedade alemã estava impossibilitando uma vivência acadêmica plena de sentido e adequada à transformação social. Isso devido à universidade ser pautada na "utilidade", o que gerava a carência de conhecimento crítico e autêntico. Assim, Benjamin (1986) propõe o seguinte:

O único caminho para tratar do lugar histórico do estudantado e da universidade é o sistema. (...) resta apenas libertar o futuro de sua forma presente desfigurada, através de um ato de conhecimento. Somente para isso serve a crítica (1986: 107).

Com efeito, pode-se dizer que a pretensão de Benjamin é fazer com que tanto os estudantes quanto os professores compreendam o verdadeiro sentido da ciência e da Erfahrung e possam se comprometer em ressignificar os conteúdos da tradição que são em prol da sociedade e do coletivo. Por conta disso, seria possível vivenciar uma formação acadêmica que acolha a experiência viva da tradição e possa deixá-la em aberto para possibilitar a reconstrução do que se encontra perdido. Benjamin remete que se redirecione a forma de relação com o mundo ou o outro, pois é inimigo da informação imediatista que não contempla a tradição.

No campo da educação, esses temas discutidos acima são significativos, pois revelam a necessidade de interromper o contínuo da história que está fadado a um tempo homogêneo e vazio. Da mesma forma, estas temáticas são relevantes para refletir sobre o campo educacional no sentido de que o rumo que a educação vem tomando, relacionado com a lógica do consumismo e do produtivismo, inviabiliza que as instituições escolares se organizem na tentativa de construir uma sociedade pautada pela memória dos seus ancestrais e pelas histórias dos sujeitos que desempenham e acarretam numa verdadeira formação válida para todos os indivíduos de uma coletividade.

Mestre em Educação pela Universidade do Extremo Sul Catarinense. Graduada em Letras-Português e Espanhol pela Universidade do Extremo Sul Catarinense. Especialização em Língua e Literatura com ênfase nos gêneros discursivos pela Universidade do Extremo Sul Catarinense. Atualmente está cursando disciplina de doutorado em Educação pela Universidade Federal de Santa Catarina. Brasileira, residente em Santa Catarina. E:mail: cissapiazza@yahoo.com.br. 
Dessa maneira, quando Benjamin diz que, "assim como a cultura não é isenta de barbárie, não o é, tampouco, o processo de transmissão da cultura" (1986: 94), compreende-se a importância de se pensar nos temas sobre história e progresso para o contexto da educação. Em outras palavras, tal relevância se deve ao fato de que as temáticas do ensaísta Benjamin nos permitem repensar e romper com os velhos convencionalismos educacionais instituídos, a fim de nos despertar sobre o quanto a lógica da história positivista pode causar ruínas e estão distantes da tradição e da Erfahrung. Desse modo, refletir sobre estes temas que o filósofo discute nos demonstra a necessidade de percorrermos outros caminhos para escapar das barbáries provocadas pelo pensamento único e pelo atual contexto neoliberal.

\section{O ENSAIO COMO FORMA EM WALTER BENJAMIN}

Nesse terceiro momento discute-se o ensaio como forma em Walter Benjamin a fim de mostrar de que modo a escrita benjaminiana pode contribuir para 0 processo educativo a partir de uma leitura dos ensaios desse filósofo alemão. O ensaio como forma insere um procedimento de símbolos e alegorias para fomentar a reflexão crítica e a resistência à subordinação a ideologias dogmáticas, pois não se sujeita a nenhum tipo de imposição, ou seja, é mais autônomo. Além disso, o ensaio não se deixa apreender facilmente, ele cria um espaço polêmico de debate e de desentendimento. Dessa maneira, Adorno (2003) ressalta que a possibilidade de autonomia e liberdade do gênero ensaio admite que se discorra sobre diversos assuntos, porém sem a obrigação de se prender em nenhum deles, pois o autor tem a possibilidade de, ao falar de determinado objeto, experimentá-lo e tentar compreendê-lo em todos os seus aspectos de acordo com a realidade daquele contexto e depois ir adiante ou retroceder conforme o pensamento do autor se direcionar. Por esse aspecto de insubordinação que:

$\mathrm{Na}$ Alemanha, o ensaio provoca resistência porque evoca aquela liberdade de espírito que, após o fracasso de um lluminismo cada vez mais morno desde a era leibniziana, até hoje não conseguiu se desenvolver

Mestre em Educação pela Universidade do Extremo Sul Catarinense. Graduada em Letras-Português e Espanhol pela Universidade do Extremo Sul Catarinense. Especialização em Língua e Literatura com ênfase nos gêneros discursivos pela Universidade do Extremo Sul Catarinense. Atualmente está cursando disciplina de doutorado em Educação pela Universidade Federal de Santa Catarina. Brasileira, residente em Santa Catarina. E:mail: cissapiazza@yahoo.com.br. 
adequadamente, nem mesmo sob as condições de uma liberdade formal, estando sempre disposta a proclamar como sua verdadeira demanda a subordinação a uma instância qualquer (ADORNO, 2003: 16).

Nesse entendimento, este artigo permitiu refletir e repensar sobre as construções lineares e racionais que se afastam do propósito educacional pautado numa educação voltada para a experiência genuína que se relaciona com 0 conhecimento e a vida humana. Em outras palavras, o ensaio benjaminiano para a educação possibilita pensar sobre o quanto o ritmo acelerado visando o progresso desordenado apenas afasta o conhecimento da tradição e da Erfahrung. Pois nessas reflexões sobre o ensaio como forma e sua contribuição para o processo educativo a partir de uma leitura benjaminiana, evidenciou-se que o ensaio traz a possibilidade de se desvencilhar de certas verdades e experimentar outras alternativas diferentes com as quais estávamos habituados.

Percebe-se que o ensaio como forma pode servir de alegoria para nos demonstrar que a educação na modernidade é pautada pela extrema razão e não permite encontrarmos uma saída, pois esta linearidade da história pautada no progresso torna o sujeito um mero consumista, que, devido à racionalidade na modernidade, limita-o a ser um produtor e consumidor ao invés de se tornar ator de sua vida. Nessa perspectiva, essa modernidade marcada pelo sistema capitalista implanta no indivíduo apenas desejos insaciáveis de consumir e trabalhar para obter mercadorias, o que resulta numa educação voltada para o mercado de trabalho, sendo ela linear, racional e direcionada conforme o sistema capitalista age.

Porém, Benjamin, com seu modo dinâmico de escrita do ir e do vir, vai romper com essa linearidade para mostrar outras dimensões da realidade histórica, pois o filósofo acredita que a história refere-se não apenas a acontecimentos lineares, e sim a episódios que o sujeito vive, que é a história do cotidiano, principalmente as micro-histórias. Dessa maneira, o modelo de escrita benjaminiano pode servir de alegoria para mostrar, no mundo da modernidade e consequentemente na educação, que é possível refletirmos sobre uma saída em relação à construção progressista e linear de educação. Ou melhor, o que constatei nesse trabalho é que este exemplo de escrita do filósofo, o ensaio como forma, poderia ser uma maneira

Mestre em Educação pela Universidade do Extremo Sul Catarinense. Graduada em Letras-Português e Espanhol pela Universidade do Extremo Sul Catarinense. Especialização em Língua e Literatura com ênfase nos gêneros discursivos pela Universidade do Extremo Sul Catarinense. Atualmente está cursando disciplina de doutorado em Educação pela Universidade Federal de Santa Catarina. Brasileira, residente em Santa Catarina. E:mail: cissapiazza@yahoo.com.br. 
de representação, assim como poderia servir de reflexão em relação à crítica que Benjamin faz da construção do moderno, ou seja, através do ensaio benjaminiano existe a possibilidade de refletirmos a respeito de uma saída desta modernidade e modelo linear e racional de educação.

Disso resulta a compreensão de que, para Benjamin, há inúmeras histórias simultâneas e é o presente que escolhe o passado que the interessa podendo optar por uma outra história. Assim o ensaio como forma possibilita, a partir do momento presente, reconstruir uma memória repleta de complexidades e riquezas capaz de mudar permanentemente o passado, pois, para Benjamin, não é o passado que determina o presente, mas sim o presente que escolhe o passado que lhe interessa. Nesse sentido, percebi, neste trabalho, que o ensaio benjaminiano permite, a qualquer tempo, compor-se de várias realidades sem torna-se vazio e sem lógica; pelo contrário, ele se mostra como uma grande contribuição para pensarmos em construir uma educação que se tenha sujeitos de sua própria história. $E$, apesar de existirmos dentro desse contexto da contemporaneidade voltado para o consumo, o que se infere é que na forma do ensaio benjaminiano podemos refletir e vislumbrar uma saída, pois sabemos que há a possibilidade de, a partir do presente, reescrevermos e reconstruirmos um outro tipo de realidade.

Desse modo, a relevância da forma do ensaio benjaminiano para o campo educacional se encontra no fato de proporcionar uma experiência que não precisa ser necessariamente com a verdade, já que o importante é experimentar e se desprender para explorar os vários aspectos que uma determinada realidade possa apresentar. Assim sendo, para a educação, o gênero ensaístico, na perspectiva benjaminiana, oportuniza a experiência de "liberar-nos de certas verdades, de modo a deixarmos de ser o que somos para ser outra coisa para além do que vimos sendo" (LARROSA, 2015: 9).

Ressalto ainda que a reflexão do ensaio como forma em Benjamin demostrou o quanto sua escrita repleta de fragmentos literários, aforismos e aglomerado de pensamentos compõe o estilo do pensamento benjaminiano que nos remete a pensar num mosaico, e conseguimos perceber o quanto o ensaio em Benjamin se constrói nesta mistura do ir e do vir imerso em totalidades que se esgotam e em

Mestre em Educação pela Universidade do Extremo Sul Catarinense. Graduada em Letras-Português e Espanhol pela Universidade do Extremo Sul Catarinense. Especialização em Língua e Literatura com ênfase nos gêneros discursivos pela Universidade do Extremo Sul Catarinense. Atualmente está cursando disciplina de doutorado em Educação pela Universidade Federal de Santa Catarina. Brasileira, residente em Santa Catarina. E:mail: cissapiazza@yahoo.com.br. 
seguida se recompõem. É, justamente, nesse exemplo de sua escrita que se encontra o grande complexo legado que Benjamin nos deixa para que possamos discernir o quanto é equivocado pensarmos em postulados dogmáticos e sistemáticos para a educação que, certamente, deve ser contrária a isso e estar embasada em experimentar e transformar o saber e não querer dar-lhe uma verdade estagnada. Nessa perspectiva, Larrosa nos diz que:

Educamos para transformar o que sabemos, não para transmitir o já sabido. Se alguma coisa nos anima a educar é a possibilidade de que esse ato de educação, essa experiência em gestos, nos permita libertar-nos de certas verdades (LARROSA, 2015: 9).

Outra consideração pertinente a se fazer nesse artigo é em relação ao quanto as temáticas benjaminianas sobre experiência e narratividade discutidas no primeiro momento deste artigo vão ao encontro da dinâmica fragmentária da escrita de Walter Benjamin. Pois tanto a etimologia do verbo ensaiar quanto do verbo experimentar remete ao ato de testar algo. E a postura de Benjamin frente a sua compreensão de experiência e seu estilo de escrever vislumbram uma atitude de abertura e experimento diante da realidade que se apresenta.

Além disso, os temas sobre história e progresso discutidos no segundo momento deste estudo também se mostram compatíveis e se relacionam com a perspectiva do ensaio benjaminiano. Pois, tanto essas temáticas quanto o estilo ensaístico do filósofo alemão fogem da concepção de linearidade e renunciam a práticas excludentes e progressistas. Nesse sentido, infere-se o quanto se pode pensar sobre todo este legado de Benjamin para o campo educacional que nos instiga a refletir sobre a necessidade de fugir dos preceitos acadêmicos tradicionais que apenas querem atender as demandas mercadológicas tão precárias e distantes de uma experiência plena no sentido que Benjamin investigou. Assim diz Larrosa:

\footnotetext{
Penso que, se a educação não quer estar a serviço do que existe, tem que se organizar em torno de uma categoria livre, não sistemática, não intencional, inassimilável, em torno de uma categoria, poderíamos dizer, que não possa ser apropriada por nenhuma lógica operativa ou funcional. (LARROSA, 2015: 12).
}

Mestre em Educação pela Universidade do Extremo Sul Catarinense. Graduada em Letras-Português e Espanhol pela Universidade do Extremo Sul Catarinense. Especialização em Língua e Literatura com ênfase nos gêneros discursivos pela Universidade do Extremo Sul Catarinense. Atualmente está cursando disciplina de doutorado em Educação pela Universidade Federal de Santa Catarina. Brasileira, residente em Santa Catarina. E:mail: cissapiazza@yahoo.com.br. 
Saliento ainda, que tanto as escolhas dos textos quanto as minhas interpretações não pretenderam abarcar a totalidade dos temas das obras benjaminianas ou esgotar suas inúmeras compreensões. Coube aqui apenas levantar questões particulares para uma observação mais atenta do ensaio como forma em Benjamin, ressaltando sua relação com o campo da educação. Se, com isso, foi possível colocar perguntas pertinentes, o artigo já cumpriu seu papel, pois novos olhares e discussões podem ser lançados ao longo dessa produção, assim como outros autores e temas podem ser inseridos neste percurso, visto que as obras benjaminianas podem ser tratadas sob diversos prismas, pois sua diversidade e seus assuntos abordados possibilitam um diálogo transdisciplinar que ultrapassa as fronteiras do conhecimento e permite debater com as áreas da filosofia, da arte, da história, da literatura, do cinema, entre tantas outras.

Outra consideração a ser feita é que toda essa percepção da modernidade em Benjamin, nos vários temas que ele discute, evidencia a ideia de "desintegridade" que a vida moderna vem demonstrando. Sob esta ótica, ao discutir o ensaio benjaminiano e os temas sobre narratividade, história e progresso, há incutido, no cerne desses assuntos, o declínio da experiência autêntica. Por isso, para o campo educacional, essas reflexões são pertinentes para pensarmos qual o real propósito da educação e em que direção ela está indo na atual situação.

Assim, ao analisar os aspectos do ensaio benjaminiano e sua intenção em compor-se de fragmentos literários, aforismos e aglomerado de pensamentos, percebe-se que este modo de escrever é condizente com uma postura que visa a procura de todas as diversas realidades que estão a nossa volta e não somente um tipo de visão. Na educação, também, deveria ter-se esse posicionamento de captar todo um conjunto de concepções, a fim de construir-se visando o coletivo e se baseando numa experiência que resultasse no amadurecimento do individuo humano e de ações significativas para o senso de comunidade.

Porém, o modo linear e individualista no qual a sociedade se encaminha reflete em nossa educação, que também está voltada para questões utilitaristas e mercadológicas. Nessa concepção, a forma do ensaio em Benjamin nos faz enxergar e refletir sobre uma outra lógica de realidade que devemos ter. Porque a

Mestre em Educação pela Universidade do Extremo Sul Catarinense. Graduada em Letras-Português e Espanhol pela Universidade do Extremo Sul Catarinense. Especialização em Língua e Literatura com ênfase nos gêneros discursivos pela Universidade do Extremo Sul Catarinense. Atualmente está cursando disciplina de doutorado em Educação pela Universidade Federal de Santa Catarina. Brasileira, residente em Santa Catarina. E:mail: cissapiazza@yahoo.com.br. 
escrita benjaminiana se mostra como um exemplo de postura que devemos discernir diante da realidade, já que ela é repleta de fragmentos que juntos se completam e demonstram uma perspectiva que se preocupa com o todo e com o acolhimento de todas as possibilidades que uma época pode conter.

Em vista disso, o ensaio benjaminiano e suas discussões referentes a experiência, narratividade, progresso e história me fizeram observar, neste trabalho, o quanto a educação privilegia e enxerga a palavra progresso de forma linear e atribuindo-Ihe um sentido como sendo a maneira mais eficaz e inteligente de desenvolver a humanidade. Sob essa ótica, Benjamin nos aponta uma perspectiva contrária a essa, pois, para ele, nossa geração, pautada nesse desenvolvimento linear, é e será cada vez mais decadente em valores e estará impossibilitada de adquirir uma experiência genuína, voltada para o coletivo e com senso de comunidade. Por isso, todas essas discussões sobre a forma do ensaio benjaminiano são fundamentais para se pensar além da nossa vida prática. $E$ assim refletirmos qual educação queremos e que preço estamos dispostos a pagar ao privilegiar todos esses aparatos tecnológicos pautados nessa visão progressista e utilitária da vida.

Mestre em Educação pela Universidade do Extremo Sul Catarinense. Graduada em Letras-Português e Espanhol pela Universidade do Extremo Sul Catarinense. Especialização em Língua e Literatura com ênfase nos gêneros discursivos pela Universidade do Extremo Sul Catarinense. Atualmente está cursando disciplina de doutorado em Educação pela Universidade Federal de Santa Catarina. 


\section{REFERÊNCIAS}

ADORNO, T. W. O ensaio como forma. Sociologia. São Paulo: Ática, 2003.

AGAMBEM, Giorgio. Infância e História: destruição da experiência e origem da história. Trad. Henrique Burigo. Belo Horizonte: Editora UFMG, 2005.

BENJAMIN, Walter. Experiência e pobreza. In: Magia e técnica, arte e política. Trad. Paulo Sérgio Rouanet. São Paulo: Brasiliense, 1986.

Magia e técnica, arte e política. Trad. por Paulo Sérgio Rouanet. (Obras Escolhidas, v. I). São Paulo: Brasiliense, 1986.

Teses sobre a filosofia da história. In: Sobre arte, técnica, magia e política. Trad. Maria Luz Moita. Lisboa: Relógio D’Água, 1989.

BENJAMIN, Walter. Documentos de cultura, documentos de barbárie. Editora Cultrix, São Paulo : 1986.

GAGNEBIN, Jeanne-Marie. História e narração em Walter Benjamin. São Paulo: Perspectiva, 1999. $\overline{1997 .}$

Sete aulas sobre linguagem, memória e história. Rio de Janeiro: Imago,

LARROSA, Jorge. Tremores. Escritos sobre experiência. Belo Horizonte: Autêntica, 2015.

LÖWY, Michael. Walter Benjamin: aviso de incêndio. Uma leitura das teses "Sobre o conceito de história". São Paulo: Boitempo, 2010.

Mestre em Educação pela Universidade do Extremo Sul Catarinense. Graduada em Letras-Português e Espanhol pela Universidade do Extremo Sul Catarinense. Especialização em Língua e Literatura com ênfase nos gêneros discursivos pela Universidade do Extremo Sul Catarinense. Atualmente está cursando disciplina de doutorado em Educação pela Universidade Federal de Santa Catarina. 